\title{
ВАРИАНТЫ ТРАНСФОРМАЦИИ РЕГИОНАЛЬНЫХ ЭЛИТ: ПРОГНОЗЫ НА ОСНОВАНИИ СИСТЕМНО-ДИНАМИЧЕСКОЙ МОДЕЛИ РЕКРУТИРОВАНИЯ ЭЛИТ В 1985-2019 ГОДАХ
}

\author{
Д.С. Жуков, Д.Г. Сельщер
}

Тамбовский государственный университет им. Г.Р. Державина, Тамбов, Россия

Цитирование: Жуков Д.С., Сельцер Д.Г. Варианты трансформации региональных элит: прогнозы на основании системно-динамической модели рекрутирования элит в 1985-2019 годах // Власть и элиты. 2021. Т. 8, № 1. С. 100-122.

DOI: https://doi.org/10.31119/pe.2021.8.1.4

Аннотация. Представлены прогностические сценарии, описываюшие трансформацию российских региональных административно-политических элит до 2035 2. и полученные в ходе компьютерных экспериментов с системно-динамической моделью рекрутирования элит. Модель реализуется посредством специального программного обеспечения Powersim Studio 10 и создана на основании данных о динамике элит в нескольких регионах Европейской части России в 1985-2019 г2. Авторь представили, помимо инерицонного, три альтернативных сиенария: "Регентство», "Вертикализаиия» и "Умеренная технократия». Старт первых двух сиенариев связан с гипотетическим смещением влияния в пользу умеренных либералов или силовиков. Исходным условием третьего сиенария является введение общенациональной системь отбора и контроля управленческих кадров для регионов. Эксперименты показывают, что инериионный сиенарий имеет меньше негативных побочных эффектов, нежели альтернативные. Вместе с тем сиенарий «Умеренная технократия» с наибольшей вероятностью допускает решение ключевых проблем развития региональных элит, т.е. то есть обеспечение их лояльности, качества и легитимности.

${ }^{1}$ Автор для связи. E-mail: seltser@yandex.ru. 
Ключевые слова: системно-динамическое моделирование, политология, административно-политические элиты, регионь России, прогнозирование.

\section{ОБЪЕКТ И МОДЕЛЬ}

Исследование основано на системно-динамической модели, которая имитирует в виртуальной среде принципы и механизмы рекрутирования региональных административно-политических элит в 1985-2019 гг. Принципы построения и функционирования системно-динамических моделей в целом и в частности данной модели представлены нами в ряде статей (см., например: [Жуков, Сельцер 2020; 2021]). «Объект моделирования состоит из двух групп элиты. Во-первых, это “административно-политическая элита высшего звена” - лица, которые имеют возможность принимать решения по существу региональной политики (включая формирование и расходование бюджетов) или влиять на подобные решения. Во-вторых, это “административная элита среднего и низшего звена” - основная масса региональных чиновников и деятелей местного самоуправления» [Жуков, Сельцер 2021].

Модель является, по существу, продуктом систематизации исследовательской литературы [Быстрова и др. 2019; 2017; Гаман-Голутвина 2012; 2006; Дука 2014; Лапина 2004; Магомедов 2000; Мохов 1998; Федорченко 2017; Чирикова, Ледяев 2017; Чирикова и др. 2014; Ledyaev et al. 2014; Ledyaev, Chirikova 2019; 2017; 2020; Turovsky, Gaivoronsky 2017] и формализации экспертных оценок [Сельцер 2006; 2017]. Она построена на эмпирической базе, включающей в себя статистику и аналитику, описывающие динамику элит в нескольких регионах Центральной России и Поволжья (Рязанская, Самарская, Тамбовская, Ульяновская области, республики Мордовия, Удмуртия и Чувашия). Поэтому географические границы, в пределах которых модель может быть корректна, охватывают Европейскую часть, за исключением столичных регионов, а также республик Северного Кавказа и некоторых других национальных республик. По каждому полугодию с 1985 по 2019 г. мы собрали сведения о том, с какой силой действовали различные механизмы рекрутирования элиты под влиянием разнообразных акторов, пытавшихся настроить эти механизмы на реализацию собственных интересов.

Модель функционирует в виртуальной среде, т.е. имитирует процессы пополнения элиты, посредством специализированного программного обеспечения Powersim Studio 10. Все исходные данные, файлы 
самой модели в формате Powersim и результаты экспериментов доступны в Интернете на сайте Центра фрактального моделирования: http:// ineternum.ru/sdm1/, http://ineternum.ru/sdm-pr/. В ряде наших предшествующих публикаций представлен математический аппарат модели [Жуков и др. 2020], а также разъяснены социальные и политические смыслы диаграммы запасов и потоков [Жуков, Сельцер 2021; 2020], которая является центральным элементом любой системно-динамической модели (рис. 1).

\section{ЗАДАЧА}

В наших прошлых статьях мы представили несколько исторических контрфактических сценариев, которые генерирует модель. Здесь мы рассмотрим несколько прогностических сценариев на 2022-2035 гг. Цель этих изысканий состоит в том, чтобы попытаться ответить на вопрос, как изменится региональная элита в результате тех или иных гипотетических событий и обстоятельств, которые возникнут, возможно, в ближайшем будущем.

Необходимо оговориться: прогностические сценарии в моделировании - это вовсе не то же самое, что и библейские пророчества. Сценарии - это рабочий инструмент для изучения свойств, состояния и трансформационного потенциала реального исследовательского объекта.

Что конкретно может прогнозировать модель? Какие данные мы имеем на выходе? Модель показывает, насколько влиятельными были/будут те или иные механизмы пополнения элиты в разное время, из каких социальных сред и в каком количестве вливались / будут вливаться новобранцы в состав элиты в течение разных периодов. Таким образом, модель позволяет судить, интересы каких социально-политических акторов обслуживала / будет обслуживать система рекрутирования элиты, насколько эффективными являлись / будут являться мероприятия тех или иных акторов (в том числе и прежде всего федерального центра) по корректировке механизмов рекрутирования. В конечном счете динамика работы механизмов и изменение состава элиты позволяют судить о том, в какой мере региональная элита является качественной (что подразумевает высокие управленческие компетенции и низкую коррумпированность), лояльной (по отношению к федеральному центру) и легитимной (в глазах местных сообществ). Полагаем, 
что попытки обеспечить все эти свойства региональных элит детерминировали элитостроительную политику федерального центра. Кроме того, понимание свойств региональных элит в будущем позволяет обоснованно прогнозировать состояние отношений в парах «федеральный центр - субъект федерации» и «региональные власти - региональный социум». От состояния таковых отношений во многом зависит стабильность политического режимы в целом.

Помимо инерционного, были получены шесть альтернативных прогностических сценариев: «Регентство», «Вертикализация», «Умеренная технократия», «Форсированная технократия», «Радикальная технократия», «Украинизация». Общий обзор этих сценариев дан в нашей предшествующей статье [Жуков, Сельцер 2021]. Здесь мы подробно представим и обсудим политические смыслы трех наиболее содержательных сценариев, которые очерчивают веер перспектив современных российских региональных элит.

\section{ПОДХОД И ИНСТРУМЕНТАРИЙ}

Какова процедура построения модели? Знания и представления опрашиваемых экспертов, а также авторов привлеченной литературы переносились посхеме в специализированную программу для моделирования. Таким образом, интуитивная имплицитная модель, функционирующая внутри сознания эксперта, становилось явной (эксплицитной) математической конструкцией, живущей своей жизнью в виртуальной среде.

Системно-динамическое моделирование (СДМ) - весьма авторитетная и очень популярная технология, которая используется и естественных и в социальных науках для решения прикладных и фундаментальных задач.

Ключевая фигура СДМ - Джей Форрестер [Форрестер 1978], который в 1960-е годы создал эту технологию, приобретшую множество последователей [Гараедаги 2010; Медоуз 2011; Armenia et al. 2014; Axelrod 2004; Choucri et al. 2007; Sorci 2015]. Любая система в СДМ представляется по определенному шаблону в виде системы резервуаров/запасов, соединенных потоками, которые регулируются вентилями. А в этой системе циркулирует какая-то субстанция - деньги, власть, люди и пр.

На рисунке 1 представлена диаграмма запасов и потоков - формальное машиночитаемое описание элементов и связей внутри системы. 


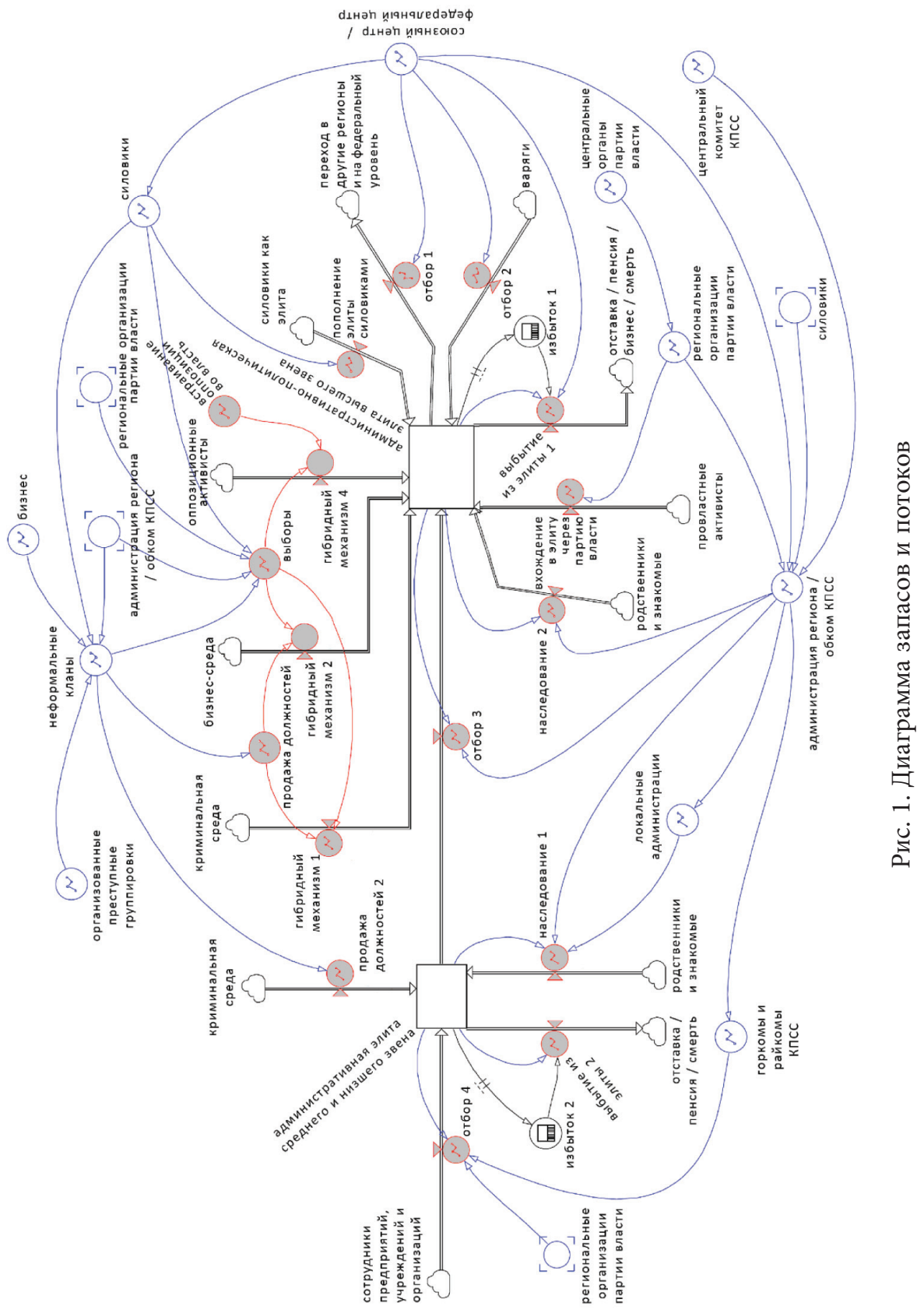


Диаграмма содержит следующие элементы:

- «Запасы», которые обозначены прямоугольниками. Это две условные группы элиты («высшее звено» и «среднее и низшее звенья»), которые являются объектами нашего исследования. По существу, запасы представляют собой две совокупности позиций в элите.

- «Потоки» (двойные стрелки). В нашем случае это каналы, по которым осуществляется социальное перемещение людей. Потоки связывают запасы, обозначая тем самым возможность карьерного роста - переходы из низших звеньев в высшее звено. Кроме того, по потокам в элиту вливаются новобранцы из разных социальных резервуаров/сред, обозначенных «облаками».

— «Механизмы» (заретушированные кружки) регулируют мощность «потоков». Это своего рода вентили, которые действуют под влиянием акторов.

- Акторы (синие кружки), которые влияют на работу механизмов: открывают или закрывают их в зависимости от своих интересов.

- Информационные коннекторы (одинарные стрелки), посредством которых связаны сами акторы. Коннекторы показывают, как акторы влияют друг на друга и на механизмы.

Условные обозначения показаны на рисунке 2. Этот рисунок также дает представление о том, как в Powersim Studio 10 ставятся компьютерные эксперименты и выводятся результирующие данные.

Экспериментатор может, условно говоря, закрыть или приоткрыть вентиль на том или ином потоке и посмотреть, как в результате наполняются или опустошаются резервуары, т.е. насколько сильны потоки из разных социальных сред в элиту в разные годы.

На каждый резервуар и поток можно поставить виртуальный датчик и считывать уровень заполнения резервуаров и силу потоков в разное время. Эти данные в виде графиков и таблиц видны на рисунке 2 по бокам и внизу от диаграммы запасов и потоков.

Компьютерные эксперименты позволяют изменять отдельные условия и события, оставляя все иные аспекты модели прежними. Это дает возможность рассматривать последствия тех или иных изменений (как реальных, так и гипотетических) изолированно «при прочих равных условиях».

Подобная задача представляется весьма нетривиальной, поскольку акторы, механизмы, запасы и потоки находятся в плотной сети взаимосвязей, а изменение даже одного условия эксперимента может иници- 


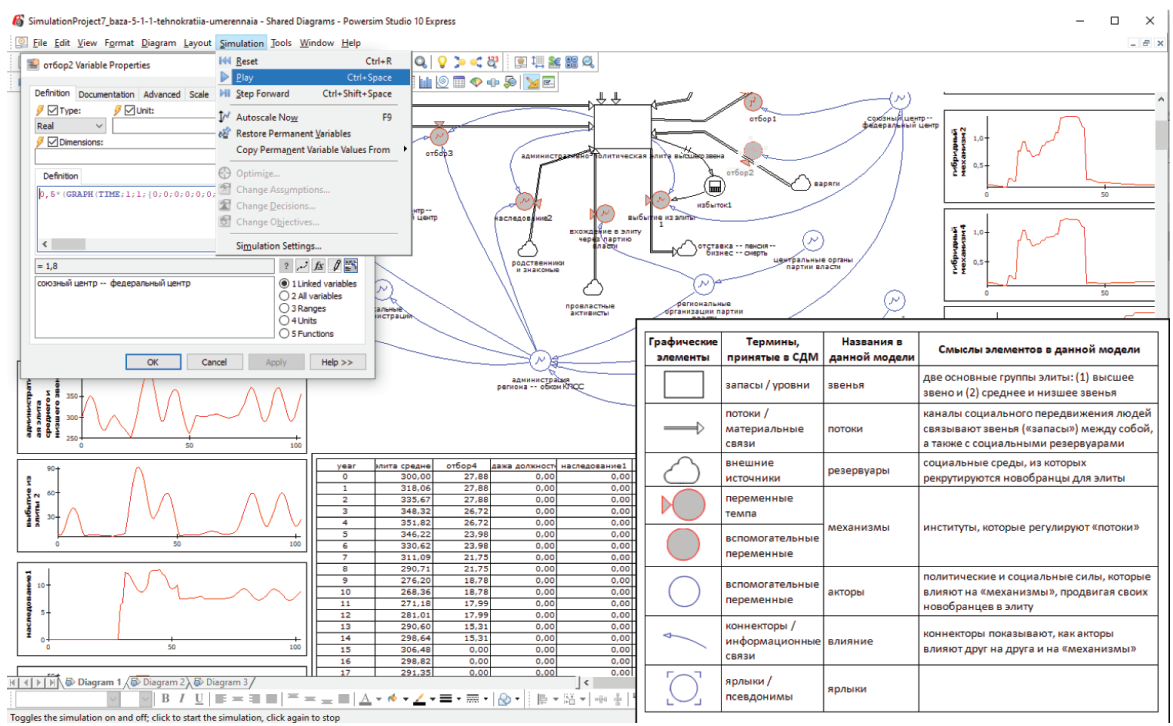

Рис. 2. Рабочее окно Powersim Studio 10

ировать процессы, которые интуитивно - на экспертном уровне крайне сложно учесть.

Модель дает возможность менять в ходе экспериментов главным образом действенность механизмов и силу влияния акторов. Событийная канва прогнозов является результатом интерпретаций. Однако не всегда это вольные фантазии, поскольку события (если это не падение метеорита) являются естественным продуктом обстоятельств и тенденций.

Какие именно данные мы получаем на выходе после обработки результатов экспериментов? Например, на рисунке 3 показан с некоторыми оговорками состав элиты - доли групп, выделенных по источникам и способам рекрутирования новобранцев. Мы видим, как меняются эти доли во времени.

\section{ИНЕРЦИОННЫЙ СЦЕНАРИЙ}

Инерционный сценарий возник из предположения, что ни один из акторов (включая федеральный центр) не попытается (а если и попытается, то не сможет) нарушить статус-кво - расклад сил вокруг системы рекрутирования элиты. 

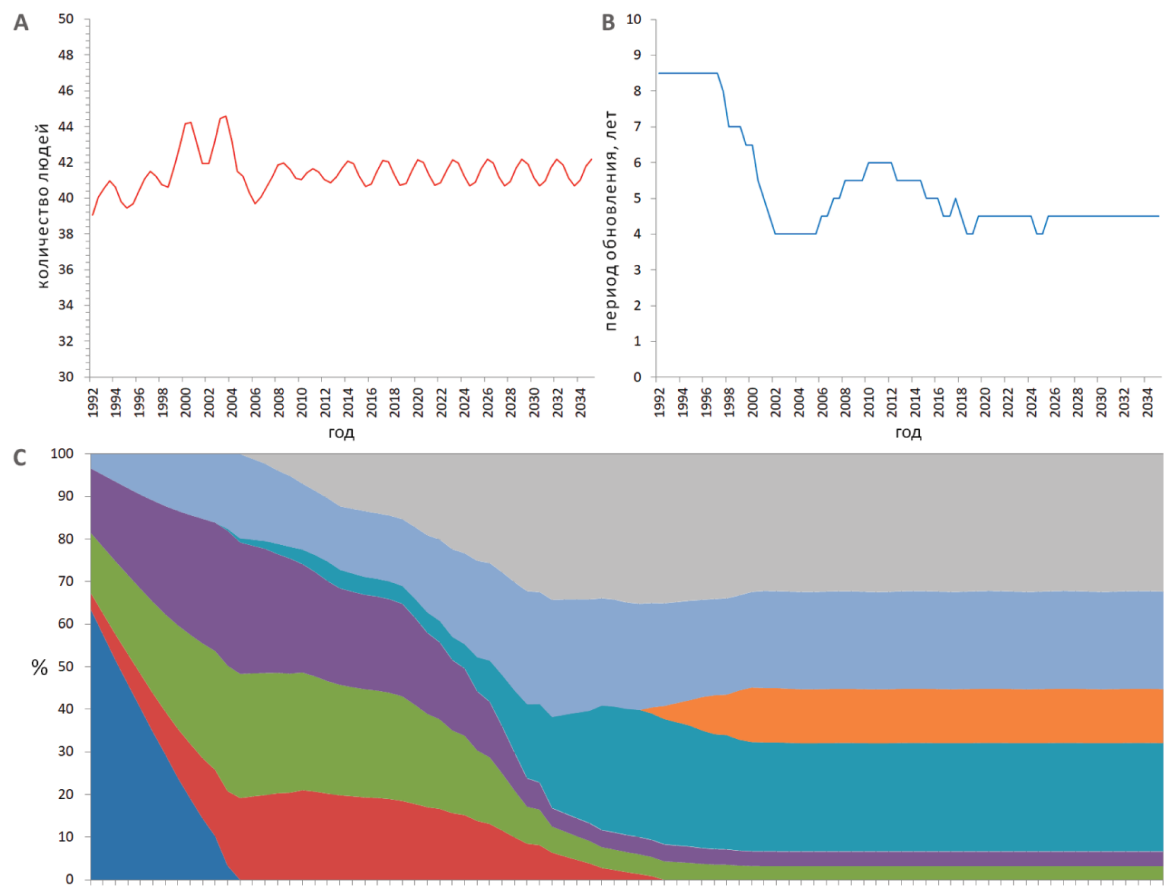

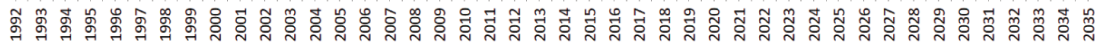
год

ш родственники и "знакомые"; наследование вхождение в элиту через партию власти

- назначение варягов

— пополнение элиты силовиками

ш встраивание оппозиции во власть через выборы и прочие механизмы шредставители бизнеса; продажа должностей и выборы

च представители криминальной среды; продажа должностей и выборы

— сотрудники предприятий, учреждений и организаций; отбори вертикальная мобильность

Рис. 3. Инерционный сценарий, высшее звено

В 2000-2010-х годах система трансформировалась под влиянием двух мощных факторов. Во-первых, это инерция, возникшая в начале 1990-х годов в результате первых решений новой российской власти в прорисовке регионального административно-политического дизайна (из главного - наличие в элите представителей оппозиции, попавшей туда через выборы в середине 1990-х годов, регионализация российской политики, ее клановость и криминализация). Во-вторых, это попытки федерального центра с начала 2000-х годов оздоровить региональные элиты, поскольку негативные тенденции, стартовавшие в начале 1990-х годов, в конце концов сформировали угрозу для целостности государства, управляемости страны, стабильности политического 
режима и его легитимности. Пытаясь решить тройственную задачу по обеспечению качества, лояльности и легитимности региональных элит, федеральный центр усилил вертикаль власти, однако в полной мере добился прогресса лишь по одному пункту - обеспечение лояльности.

В инерционном сценарии федеральный центр может рассчитывать на поддержку нескольких групп элиты, в совокупности составляющих большинство - силовиков, варягов и выдвиженцев партии власти.

Вместе с тем в инерционный сценарий перекочевал и негативный побочный эффект, обнаружившийся уже сейчас, - резкое усиление в элите той группы, которую мы условно назвали «родственниками и знакомыми». «Это, в сущности, люди, которые получили элитные позиции, постольку состояли в разного рода личных отношениях с представителями уже существующей элиты. Механизм рекрутирования таких людей мы обозначили как “наследование”. Это, конечно, также условное название. Однако оно, как представляется, указывает на сущность описываемого явления. Рекрутирование элиты на основании личных связей порождено естественным стремлением элиты как социальной группы к замыканию, наследованию и воспроизводству в поколениях своего статуса. Это классическая тенденция превращения элиты в сословие» [Жуков, Сельцер 2021]. Именно «родственники и знакомые» воспользовались усилиями государства по выдворению из элиты криминала и оппозиции.

Наличие довольно многочисленной и стабильной группы «родственников и знакомых» вплоть до 2035 г. (без тенденции к снижению численности) в инерционном сценарии препятствует легитимации местной элиты, а также является источником коррупции и невысокого уровня управленческого мастерства местных деятелей. Тем не менее этот сценарий не угрожает быстротечным крахом региональных режимов и дестабилизацией взаимодействия между федеральным центром и регионами.

\section{«РЕГЕНТСТВО»}

Сценарий «Регентство» предусматривает оставление В.В. Путиным поста президента в 2024 г. Среди фракций федеральной элиты наибольшее влияние получили представители высшего чиновничества и-крупного бизнеса. Эти группы сосредоточились вокруг умеренно либерального компромиссного президента, отстранив силовиков. 
Преемники-регенты, стремясь стабилизировать режим, опирались в регионах на партию власти и бизнес. Партия власти казалась регентам наиболее контролируемой силой, а бизнес представлял собой наиболее желанного партнера. Поэтому влияние этих групп на механизмы формирования элит увеличилось. Кроме того, произошло частичное восстановление роли выборов как канала рекрутирования элит. Реанимация выборных механизмов стала, по существу, предложением компромисса с локальными социополитических акторами.

Основная ставка «регентства» - партия власти, то есть произойдет формирование своеобразной неопартократии. Возникшая в наше время полуторапартийная система обеспечивает, казалось бы, необходимые предпосылки для легкой реализации такого сценария.

В результате подобной политики - весьма умеренной и осторожной - в высшем звене элиты закономерно сократились до минимума доли силовиков и варягов. Однако, вопреки задачам новой кадровой политики, основными ее бенефициарами стали не бизнес и даже не партия власти (рис. 4).

Представительство бизнеса в элите оказалось ничтожно мало: 4,2 \% к 2027 г. и далее. Доля выдвиженцев партии власти, хотя и возросла до приблизительно 30 \% к 2035 г., увеличилась весьма незначительно (в начале «Регентства» партийцы занимали около четверти позиций в элите). И хотя эти люди сформировали весьма обширную группу в региональной элите, они оказались фактически единственной влиятельной силой на местах, на которую мог бы опереться федеральный центр. Спустя довольно небольшой промежуток времени центр, таким образом, утратил лояльное большинство в элите, т.е. то большинство, которого удалось добиться в ходе выстраивания вертикали власти.

Благодаря политике регентов наибольший вес приобрели «родственники и знакомые» (52,2 \% позиций к 2027 г. и далее), фактически превратившиеся в «сословных управленцев»: «Таким образом, все хитрые кадровые маневры преемников с целью добиться некоего демократического консенсуса, вопреки их воле и намерениям, привели лишь к одному значимому результату - к форсированию старой тенденции и замыканию управленческой элиты» [Жуков, Сельцер 2021].

Безусловно, такая наследственная, предельно коррумпированная и, в сущности, недееспособная элита не могла не вызвать ненависть локальных сообществ. В российских условиях подобное отношение экстраполировалось и на те части региональной элиты, которые были 

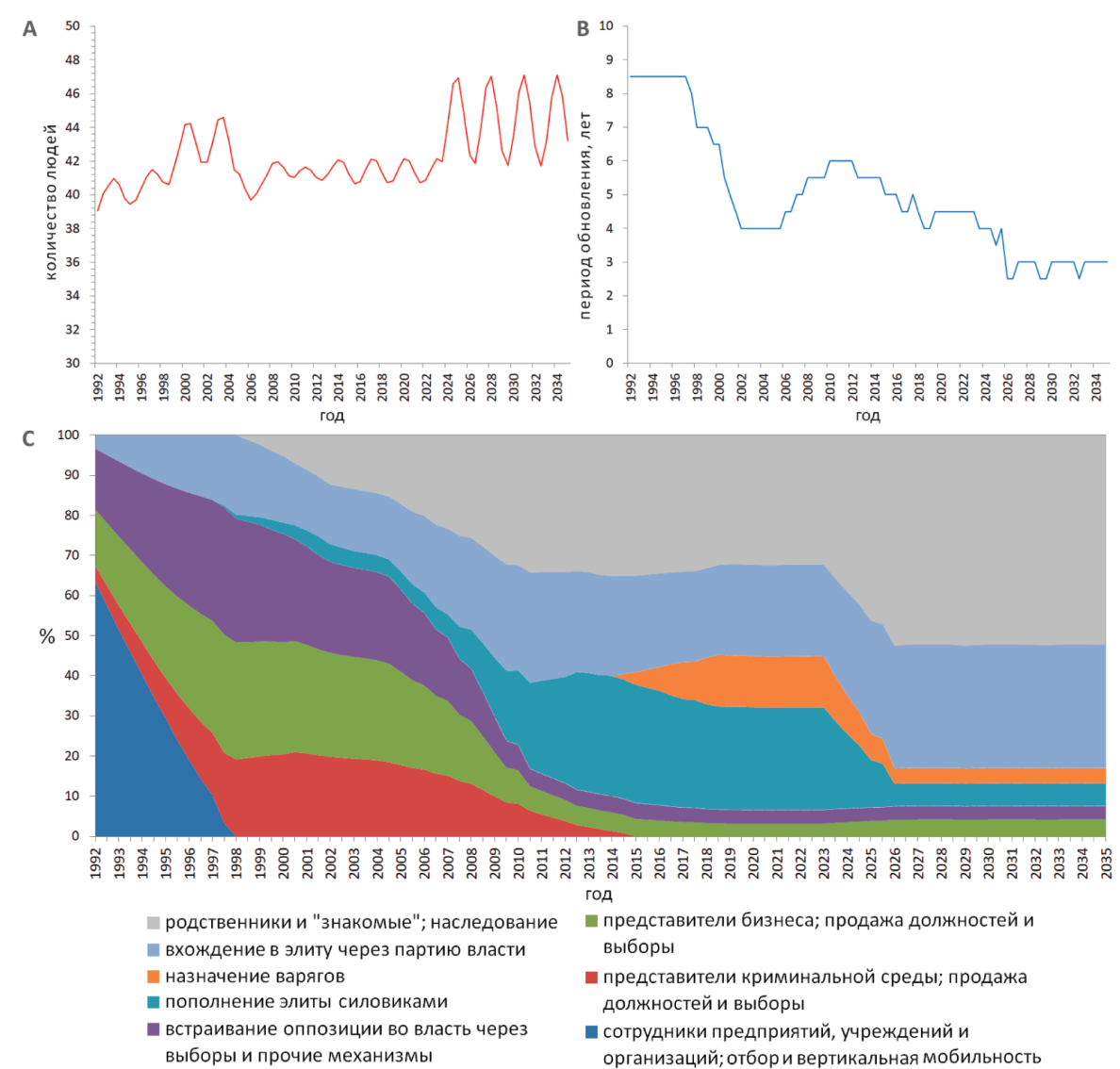

год

Рис. 4. Сценарий «Регентство», высшее звено

ставленниками федерального центра. Власть в регионах утратила легитимность на фоне стихийных меритократических представлений российского общества.

В целом результаты политики «Регентства» в регионах представляются катастрофическими уже в краткосрочной перспективе.

\section{ВЕРТИКАЛИЗАЦИЯ}

Сценарий «Вертикализация» также стартует в 2024 г. в результате гипотетического ухода В.В. Путина с поста президента. В отличие от предшествующего сценария, власть переходит к представителям силового блока. Ключевая проблема любых преемников, как умеренных либера- 
лов, так и силовиков, заключалась в том, чтобы стабилизировать режим, в том числе отношения по линии «центр - регионы». Однако для решения этой проблемы различные фракции федеральной элиты предпочитали использовать, конечно, разные средства, т.е. те, которые более соответствовали их интересам и управленческому опыту.

Поэтому преемники-силовики, стремясь упрочить свою опору в регионах, сделали ставку на решительное пополнение местных элит варягами (прямыми эмиссарами центра) и выходцами из силовых ведомств. Необходимо отметить, что та и другая группа действительно по определению лояльны федеральному центру и обладают существенно бо́льшими управленческими компетенциями, нежели иные группы (за исключением карьерных служащих - веберовской бюрократии). Таким образом, «преемники попытались воспроизвести наиболее эффективные рецепты путинской политики в отношении регионов и региональных элит. Речь идет об усилении вертикали власти... Партия власти была фактически преобразована в политическое крыло силовых структур. Значение выборов как способа рекрутирования элит было сведено к нулю» [Жуков, Сельцер 2021].

Вычислительные эксперименты показывают, что политика вертикализации (рис. 5) оказалась предельно успешной с точки зрения достижения непосредственных целей. Уже через несколько лет после ее старта (приблизительно к 2027-2028 гг.) около 98 \% позиций в элите заняли силовики и варяги. Им удалось практически полностью вычистить из элиты даже «родственников и знакомых». Так сильно потеснить эту группу не смогли (в других сценариях) ни партия власти, ни бизнес, ни даже криминал.

Политика преемников-силовиков обеспечила решения двух проблем элитостроительства - обеспечение качества и лояльности элиты. Однако, полагаем, такая политика имела критический негативный побочный эффект: «чужое» для местных сообществ ядро региональной элиты не могло добиться легитимности. Традиционные способы приобретения легитимности через имитацию выборных процедур и инкорпорирование представителей разнообразных социальных сил были чужды преемникам в данном сценарии. В результате нарастала отчужденность элиты от локального общества, разрыв связей от управляемых к управляющим, расширение контрэлиты и рост ее агрессивности, проблемы с выработкой баланса между разнообразными силами (как внутри регионов, так и по линии «центр - регионы»). 

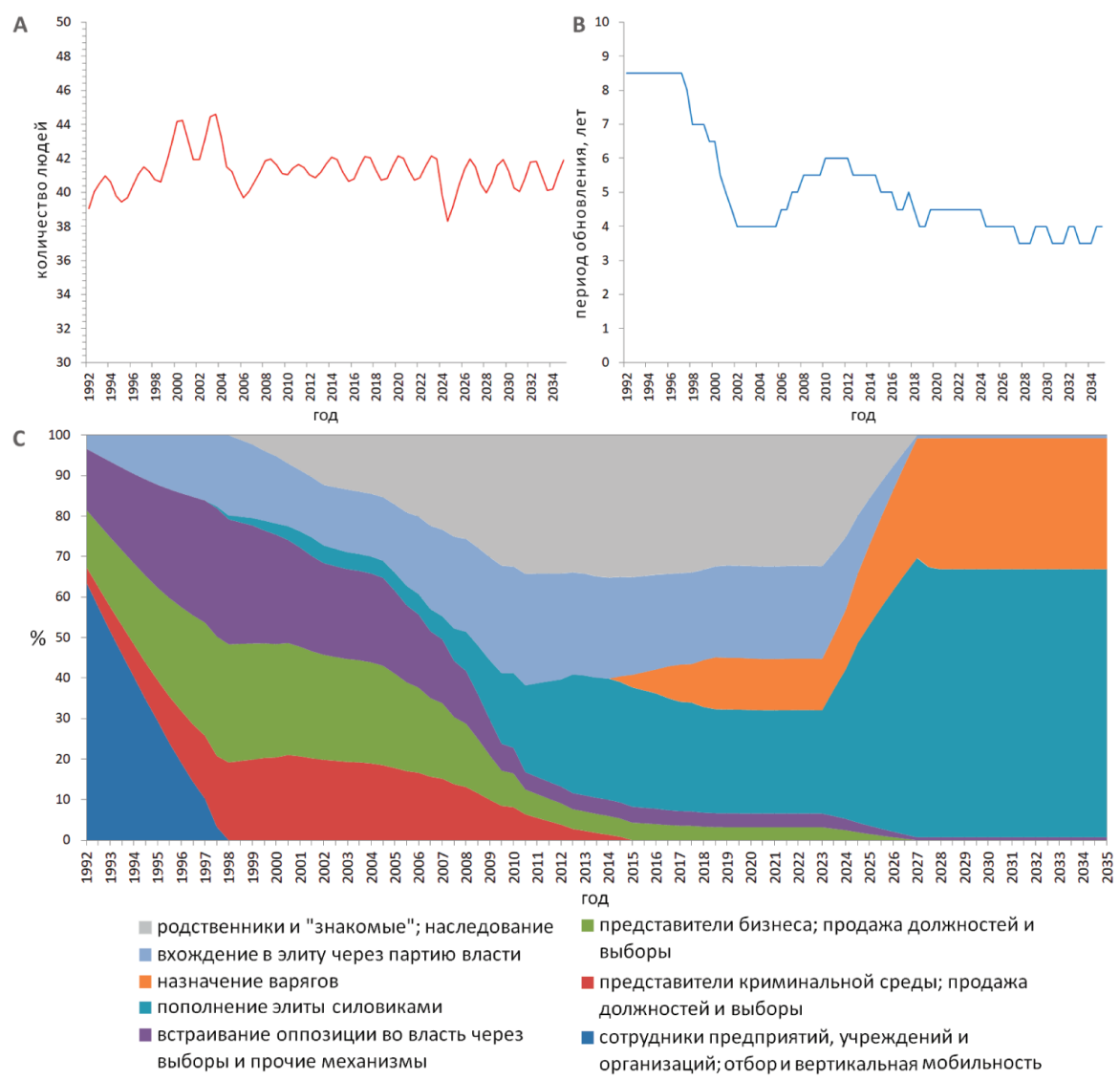

Рис. 5. Сценарий «Вертикализация», высшее звено

Таким образом, вычислительные эксперименты показывают, что современная система рекрутирования элиты позволяет в кратчайшие сроки провести вертикализацию управления. Однако такая политика «закручивания гаек», в том случае если она выходит за разумные границы, имеет весьма сильные контрпродуктивные побочные эффекты.

\section{УМЕРЕННАЯ ТЕХНОКРАТИЯ}

Следующий сценарий - «Умеренная технократия» - предусматривает формирование общенациональной системы кадрового контроля со стороны федерального центра. Подобная система соединяет черты 
номенклатурных принципов фильтрации кадров и регулирования карьерных треков с современными системами сбора и обработки массовых персональных данных.

До недавнего времени в постсоветской России не было институтов, которые имели бы технические возможности для решения подобного рода задач. Номенклатурная система советского периода поддерживалась благодаря сращению партии и государства и наличию разветвленной иерархической сети партийных комитетов и организаций. Обладая развитой иерархией, начиная от первичек и заканчивая высшими союзными партийными органами, структура осуществляла отбор представителей внеэлитной среды, следила за их продвижением, регулировала его, оценивала кадры номенклатуры и отбирала кандидатов на более высокие уровни на основании единообразной системы критериев. После департизации 1991 г. такие задачи стали и неактуальны, и организационно неосуществимы.

Однако современные технические возможности информационного общества (включая масштабные средства мониторинга и сбора больших данных, а также внедрение искусственного интеллекта для их обработки и анализа) объективно достаточны для того, чтобы формировать государственную политику относительно отдельного человека. Возникли инструменты для выстраивания в полном смысле слова персонально-ориентированной политики. Для этого более нет нужды в громоздких организационных структурах типа КПСС. «Уже сейчас созданы и испытываются в разных странах отдельные компоненты систем рейтингования чиновников (и даже простых граждан) на основании разнообразных исчисляемых индикаторов» [Жуков, Сельцер 2021].

Таким образом, во всех вариантах технократического сценария государство (федеральный центр) запустил механизмы отбора и карьерного роста, насыщая низшие и средние звенья элиты талантливыми выходцами из внеэлитной среды, а верхнее звено - профессиональными карьерными служащими со средних управленческих уровней.

В результате карьерные служащие, заняли около 26 \% к 2035 г. (рис. 6). Вместе с силовиками и варягами они составили профессиональную и лояльную опору федерального центра в региональной политике. «Родственники и знакомые», хотя и были частично вытеснены, сохранили до 20-23 \% в 2026-2035 гг. в среднем и низшем звеньях. 

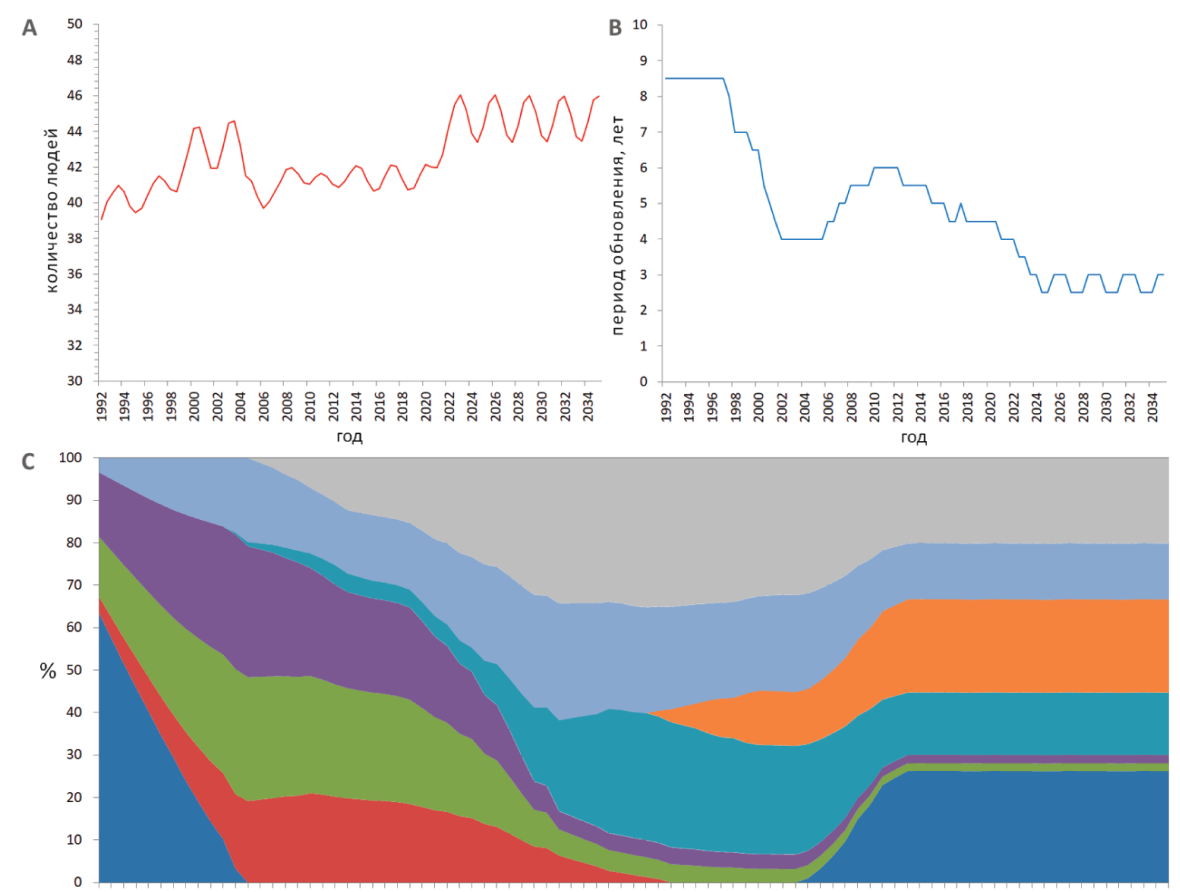

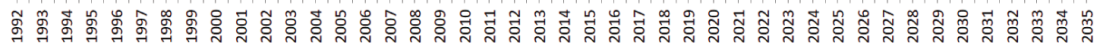
год

шодстенники и "знакомые"; наследование п представители бизнеса; продажа должностей и в вхождение в элиту через партию власти выборы

- назначение варягов

пополнение элиты силовиками

в встраивание оппозиции во власть через выборы и прочие механизмы

ш представители криминальной среды; продажа должностей и выборы

сотрудники предприятий, учреждений и организаций; отбори вертикальная мобильность

Рис. 6. Сценарий «Умеренная технократия», высшее звено

Однако во всех звеньях элиты можно наблюдать существенное сокращение минимального периода обновления: до 2,5-3,5 лет (рис. 6, 7). Это критические величины. Новобранцы-технократы вытеснили старые группы, прежде всего «родственников и знакомых». Борьба за позиции в элите резко обострилась, угрожая внутриэлитными расколами.

Такая острая ситуация обусловлена тем, что создание механизмов отбора и карьерного продвижения в этом сценарии осуществлялось параллельно с сохранением механизмов «наследования». Сценарий «Радикальная технократия» предусматривает запрет на «наследование» позиций в административно-политической элите. Это вполне предсказуемо привело к исчезновению «потомственных управленцев» и ослаблению внутриэлитного противостояния (рис. 8). 

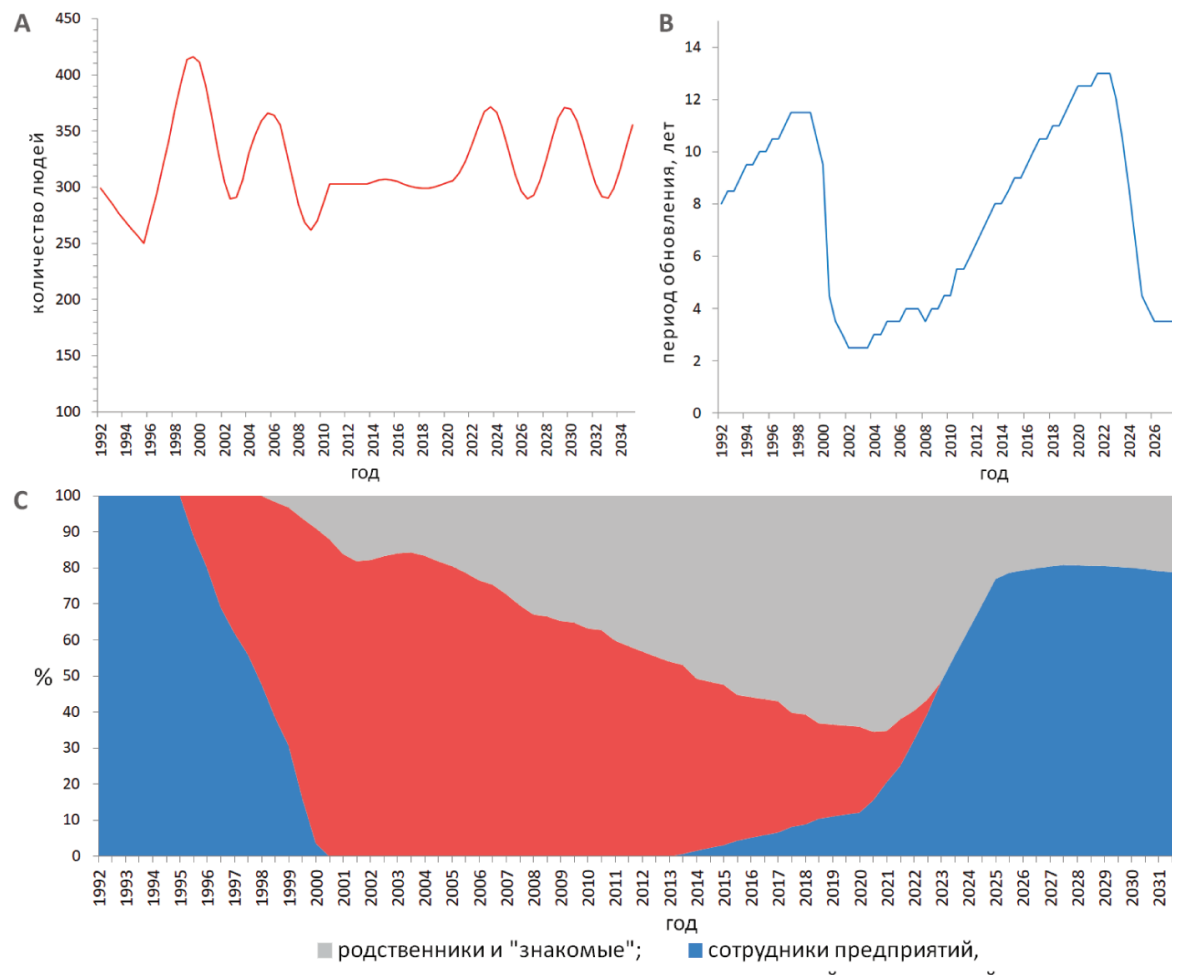

Рис. 7. Сценарий «Умеренная технократия», низшее и среднее звенья

\section{ЗАКЛЮЧЕНИЕ}

Вычислительные эксперименты показывают, что инерционный сценарий (при всех его недостатках) максимально использует потенциал существующей системы рекрутирования региональной элиты. Таким образом, данная политика выжимает максимальную пользу из существующих механизмов рекрутирования в плане обеспечения лояльности и относительного качества и легитимности элит.

Варианты, которые могут быть предложены некими гипотетическими приемниками В.В. Путина - умеренными либералами или государственниками силовиками, скорее всего, не могут быть успешными, поскольку реализуются посредством включения/выключения, усиления/ ослабления ныне действующих механизмов рекрутирования в существующей конфигурации основных акторов. Ни демократизация и новый компромисс, которые могут быть предложены преемниками-либе- 

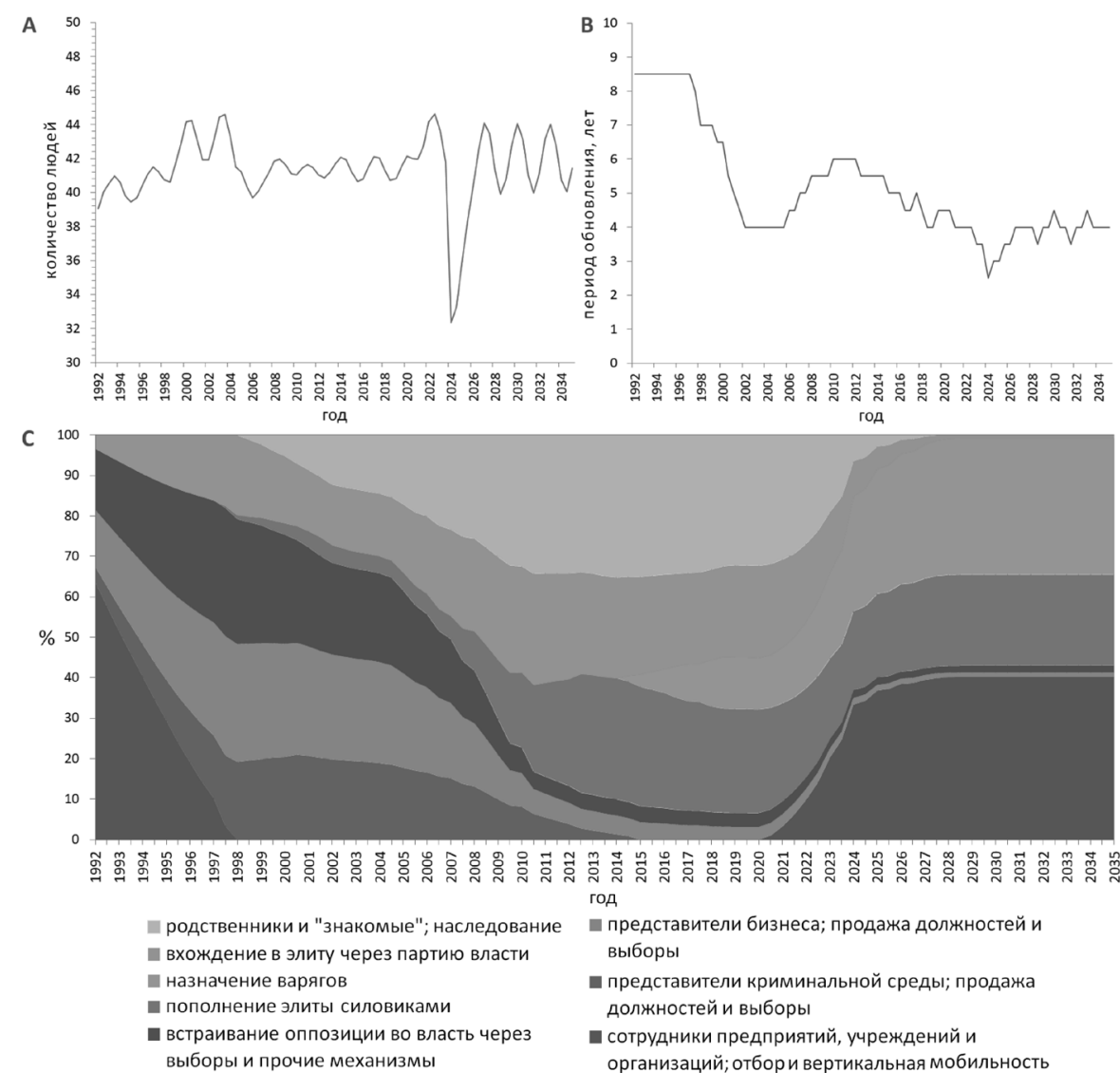

год

Рис. 8. Сценарий «Радикальная технократия», высшее звено

ралами, ни «закручивание гаек», которое может быть инициировано преемниками-силовиками, в рассмотренной модели не вели к сущностной трансформации правил игры вокруг элитозамещения. Смещение центра силы - изменение баланса (в любую сторону) - не ведет к лучшим исходам, нежели инерционный сценарий. Комбинаторная эволюция, осуществляющаяся посредством смены пропорций компонентов, исчерпала себя. Моделирование показало, что без качественной трансформации целей элитостроительства, правил игры и конфигурации акторов, допущенных к механизмам элитозамещения, невозможно создать лучшую перспективу.

Одним из возможных вариантов такой качественной трансформации в наших экспериментах была технократическая политика. Эта 
политика предусматривала запуск (на основе новых информационных систем) единого федерального кадрового контроля на всех уровнях, создание упорядоченной нормативной базы карьерного роста, а также (в некоторых экспериментах) пресечение механизмов «наследования», т.е. воспроизводства «родственников и знакомых» как наиболее влиятельной группы элиты. Моделирование показало, что разнообразные технократические вариации в той или иной мере позволяют решить ключевые проблемы строительства региональных элит: обеспечение их качества, легитимности и лояльности.

\section{Финансирование}

Исследование выполнено при поддержке РФФИ, проект № 20-011-00105а.

\section{Литература}

Быстрова А.С., Даугавет А.Б., Дука А.В., Колесник Н.В., Невский А.В., Тев Д.Б. Институционализация политической элиты: источники рекрутирования и карьера // Власть и элиты. 2019. Т. 6, № 2. С. 24-66.

Быстрова А.С., Даугавет А.Б., Дука А.В., Тев Д.Б. Региональные властные группы: основные социально-структурные характеристики и роль в развитии современного российского общества // Власть и элиты. 2017. Т. 4. C. 147-169.

Гаман-Голутвина О.В. Метафизические измерения трансформаций российских элит // Политическая концептология. 2012. № 3. С. 38-53.

Гаман-Голутвина О.В. Политические элиты России: вехи исторической эволюцию. М.: РОССПЭН, 2006. 448 с.

Гараедаги Дж. Системное мышление. Как управлять хаосом и сложными процессами: Платформа для моделирования архитектуры бизнеса. Минск: Гревцов Букс. 2010. 480 с.

Дука А.В. Власть между традиционностью и современностью (элиты российской периферии) // Власть и элиты. 2014. Т. 1. С. 399-436.

Жуков Д.С., Сельцер Д.Г. Взгляд в будущее: системно-динамическое моделирование политической трансформации региональных элит (Россия, 20212035 гг.) // Журнал политических исследований. 2021. Т. 5, № 3. С. 23-55. doi: 10.12737/2587-6295-2021-5-3-23-55.

Жуков Д.С., Сельцер Д.Г. «Развилка» 1996 года и российские региональные элиты: гипотетические сценарии трансформации // Власть и элиты. 2020. Т. 7 , № 1. C. 46-75.

Жуков Д.С., Сельцер Д.Г., Барабаш Н.С. Системно-динамическая модель воспроизводства региональных элит в СССР и России // Инноватика и экспертиза: научные труды. 2020. № 1. С. 90-102. 
Лапина Н.Ю. Региональные элиты: процессы формирования и механизмы взаимодействия в современном российском обществе: автореф. дис. ... д-ра полит. наук. М., 2004. 39 с.

Магомедов А.К. Мистерия регионализма: региональные правящие элиты и региональные идеологии в современной России: модели политического воссоздания «снизу» (сравнительный анализ на примере республик и областей Поволжья). М.: МОНФ, 2000. 224 с.

Медоуз Д. Азбука системного мышления. М.: Бином; Лаборатория знаний, 2011. 343 c.

Мохов В.П. Эволюция региональной политической элиты России (19501990 гг.). Пермь: ПГТУ, 1998. 256 с.

Сельцер Д.Г. Взлеты и падения номенклатуры. Тамбов: Тамбовполиграфиздат, 2006. 592 c.

Сельщ,р Д.Г. Рекрутирование локальной административной элиты России: исходные данные для построения системно-динамической модели // Pro nunc. Современные политические процессы. 2017. № 2. С. 27-32.

Федорченко С.Н. Государственная кадровая политика в Советском Союзе и современной России: политико-философский анализ. М.: ИНФРА-М, 2017. $154 \mathrm{c}$.

Форрестер Дж. Мировая динамика. М.: Наука, 1978. 168 с.

Чирикова А.Е., Ледяев В.Г. Власть в малом российском городе. М.: Издат. дом НИУ ВШЭ, 2017. 414 с.

Чирикова А.Е., Ледяев В.Г., Сельиер Д.Г. Власть в малом российском городе: конфигурация и взаимодействие основных акторов // Полис. Политические исследования. 2014. № 2. С. 88-105.

Armenia S., Carlini C., Onori R., Saullo A.P. Policy modeling as a new area for research: perspectives for a systems thinking and system dynamics approach? // 2nd International Symposium "Systems Thinking for a Sustainable Economy. Advancements in Economic and Managerial Theory and Practice". Roma: Universitas Mercatorum, 2014. P. 1-22.

Axelrod R. Modeling Security Issues of Central Asia. Ann Arbor: University of Michigan, 2004. 23 p.

Choucri N., Goldsmith D., Madnick S., Mistree D., Morrison, J. B., Siegel M. Using system dynamics to model and better understand state stability // MIT Sloan Research Paper. 2007. № 4661-07. P. 1-42. URL: https://ssrn.com/abstract=1011230 (дата обращения: 01.12.2021).

Ledyaev V., Chirickova A., Seltser D. Who governs? Power in the local Russian community // Journal of Political Power. 2014. Vol. 7, Issue 2. P. 211-231.

Ledyaev V.G., Chirikova A.E. Governors and local elites in Russia: patterns of interaction // European politics and society. 2019. Vol. 20, Issue 3. P. 315-332.

Ledyaev V.G., Chirikova A. Power in local Russian communities: patterns of interaction between legislative and executive branches of local government // Urban Affairs Review. 2017. Vol. 53, Issue 6. P. 990-1024. 
Ledyaev V., Chirikova A. Business in the power structure of small Russian towns // Europe-Asia Studies. 2020. T. 72, № 4. P. 686-711.

Sorci P. Measuring the impact of a state's legal and organizational framework on social capital through system dynamics modeling // Rangsit Journal of Social Sciences and Humanities. 2015. Vol. 2, Issue 2. P. 49-65.

Turovsky R., Gaivoronsky Y. Russia's regions as winners and losers: Political motives and outcomes in the distribution of federal government transfers // European Politics and Society. 2017. Vol. 18, № 4. P. 529-551.

\section{VARIANTS OF TRANSFORMATION OF REGIONAL ELITES: PREDICTIONS BASED ON A SYSTEM DYNAMIC MODEL OF RECRUITING ELITES IN 1985-2019 \\ D. Zhukov, D. Seltser}

Citation: Zhukov D., Seltser D. Varianty transformatsii regional'nykh elit: prognozy na osnovanii sistemno-dinamicheskoy modeli rekrutirovaniya elit v 1985-2019 godakh [Variants of transformation of regional elites: predictions based on a system dynamic model of recruiting elites in 1985-2019]. Vlast' $i$ elity [Power and Elites], 2020, 8 (1): 100-122. (in Russian)

DOI: https://doi.org/10.31119/pe.2021.8.1.4

Annotation. This paper demonstrates predictive scenarios describing the transformation of Russian regional administrative and political elites up until 2035. The scenarios were developed in computer experiments with a system dynamic model for recruiting elites. The model is implemented via special software Powersim Studio 10. The model was created on the basis of data on the dynamics of elites in several regions of the European part of Russia in 1985-2019. In addition to an inertial scenario, the authors presented three alternative scenarios: "Regency", "Verticalization", and "Moderate technocracy". The initiation of the first two scenarios is due to a hypothetical shift of influence in favor of moderate liberals or the siloviki (securocrats). The initial condition for the third scenario is the introduction of a nationwide system of selection and control of administrative personnel for the regions. Experiments show that the inertial scenario has fewer negative side effects than alternative scenarios. At the same time, the "Moderate Technocracy" scenario most likely offers the solution to the key problems of the development of regional elites - that is, ensuring their loyalty, quality, and legitimacy. 
Keywords: system dynamics simulation, political science, administrative and political elite, regions of Russia, forecasting.

\section{References}

Bystrova A.S., Daugavet A.B., Duka A.V., Kolesnik N.V., Nevskiy A.V., Tev D.B. Institutsionalizatsiya politicheskoy elity: istochniki rekrutirovaniya i kar'yera [Institutionalization of the political elite: sources of recruitment and career]. Vlast' $i$ elity [Power and elites]. 2019, 6 (2), pp. 24-66. (In Russian)

Bystrova A.S., Daugavet A.B., Duka A.V., Tev D.B. Regional'nyye vlastnyye gruppy: osnovnyye sotsial'no-strukturnyye kharakteristiki i rol' v razvitii sovremennogo rossiyskogo obshchestva [Regional power groups: main social and structural characteristics and role in the development of modern Russian society]. Vlast' $i$ elity [Power and elites], 2017, 4, pp. 147-169. (In Russian)

Gaman-Golutvina O.V. Metafizicheskie izmereniya transformatsiy rossiyskikh elit [Metaphysical measurements of transformations of Russian elites]. Politicheskaya kontseptologiya [Political Conceptology], 2012, (3), pp. 38-53. (In Russian)

Gaman-Golutvina O.V. Politicheskie elity Rossii: vekhi istoricheskoy evolyutsiyu. [Political Elites of Russia: Milestones in Historical Evolution]. Moscow, ROSSPEN Publ., 2006. (In Russian)

Gharajedaghi J. Sistemnoe myshlenie. Kak upravlyat' khaosom i slozhnymi protsessami: Platforma dlya modelirovaniya arkhitektury biznesa [Systems Thinking: Managing Chaos and Complexity: A Platform for Designing Business Architecture]. Minsk, Grevtsov Books Publ. 2010. (In Russian)

Duka A.V. Vlast' mezhdu traditsionnost'yu i sovremennost'yu (elity rossiyskoy periferii). Vlast' i elity [Power and elites], 2014, 1, pp. 399-436. (In Russian)

Zhukov D.S., Seltser D.G. Vzglyad v budushcheye: sistemno-dinamicheskoye modelirovaniye politicheskoy transformatsii regional'nykh elit (Rossiya, 20212035 gg.) [A look into the future: System-dynamic modeling of the political transformation of regional elites (Russia, 2021-2035)]. Zhurnal politicheskikh issledovaniy [Journal of Political Research]. 2021, (3), pp. 23-55. DOI: 10.12737/2587-62952021-5-3-23-55. (In Russian)

Zhukov D.S., Seltser D.G. «Razvilka» 1996 goda i rossiyskiye regional'nyye elity: gipoteticheskiye stsenarii transformatsii [The bifurcation of 1996 and Russian regional elites: Hypothetical scenarios of transformation]. Vlast' $i$ elity [Power and elites], 2020, 7(1), pp. 46-75. (In Russian)

Zhukov D.S., Seltser D.G., Barabash N.S. Sistemno-dinamicheskaya model' vosproizvodstva regional'nykh elit v SSSR i Rossii [System dynamic model of reproduction of regional elites in the USSR and Russia]. Innovatika i ekspertiza: nauchnyye trudy [Innovation and Expertise: Research Publications], 2020, 1, pp. 90-102. (In Russian)

Lapina N.Y. Regional'nyye elity: protsessy formirovaniya i mekhanizmy vzaimodeystviya $v$ sovremennom rossiyskom obshchestve: avtoreferat dis. ...doktora politicheskikh nauk [Regional elites: processes of formation and mechanisms of interaction in 
modern Russian society: abstract of dis. ... doctors of political sciences]. Moscow, 2004. 39 p. (In Russian)

Magomedov A.K. Misteriya regionalizma: regional'nyye pravyashchiye elity i regional'nyye ideologii v sovremennoy Rossii: modeli politicheskogo vossozdaniya «snizu» (sravnitel'nyy analiz na primere respublik i oblastey Povolzhya) [Mystery of regionalism: regional ruling elites and regional ideologies in modern Russia: models of political reconstruction "from below" (comparative analysis on the example of the republics and regions of the Volga region)]. Moscow, MONF, 2000. (In Russian)

Meadows D. Azbuka sistemnogo myshleniya [Thinking in Systems: A Primer]. Moscow, Laboratory of Knowledge Publ., 2011. (In Russian)

Mokhov V.P. Evolyutsiya regional'noy politicheskoy elity Rossii (1950-1990 gg.) [The evolution of the regional political elite of Russia (1950-1990)]. Perm, PSTU Publ., 1998. (In Russian)

Seltzer D.G. Vzlety i padeniya nomenklatury [The ups and downs of the nomenclature]. Tambov, OGUP Tambovpolygraphizdat Publ., 2006. (In Russian)

Seltser D.G. Rekrutirovanie lokal'noy administrativnoy elity Rossii: iskhodnye dannye dlya postroeniya sistemno-dinamicheskoy modeli [Recruiting the local administrative elite of Russia: initial data for building a system-dynamic model]. Pro nunc. Sovremennye politicheskie protsessy [Pro nunc. Modern political processes], 2017, (2), pp. 27-32. (In Russian)

Fedorchenko S.N. Gosudarstvennaya kadrovaya politika v Sovetskom Soyuze $i$ sovremennoy Rossii: politiko-filosofskiy analiz [State personnel policy in the Soviet Union and modern Russia: political and philosophical analysis]. Moscow, Research and Publishing Center INFRA-M Publ., 2017. (In Russian)

Forrester J. Mirovaya dinamika [World dynamics]. Moscow, Science Publ. 1978. (In Russian)

Chirikova A.E., Ledyaev V.G. Vlast'v malom rossiyskom gorode [Power in a small Russian city]. Moscow, HSE Publishing House, 2017. (In Russian)

Chirikova A.E., Ledyaev V.G., Seltser D.G. Vlast' v malom rossiyskom gorode: konfiguratsiya i vzaimodeystvie osnovnykh aktorovPredposylki i osnovnye etapy detsentralizatsii gosudarstvennoy vlasti v Rossii [Power in a small Russian city: configuration and interaction of major actors]. Polis. Politicheskie issledovaniya [Policy. Policy research], 2014, (2), pp. 88-105. (In Russian)

Armenia S., Carlini C., Onori R., Saullo A. P. Policy modeling as a new area for research: perspectives for a systems thinking and system dynamics approach? 2nd International Symposium "Systems Thinking for a Sustainable Economy. Advancements in Economic and Managerial Theory and Practice". Roma, Universitas Mercatorum Publ., 2014, pp. 1-22.

Axelrod R. Modeling Security Issues of Central Asia. Ann Arbor, University of Michigan Publ., 2004.

Choucri N., Goldsmith D., Madnick S., Mistree D., Morrison, J. B., Siegel M. Using system dynamics to model and better understand state stability. MIT Sloan 
Research Paper, 2007, (4661-07), pp. 1-42. Available at: https://ssrn.com/ abstract=1011230 (accessed: 02 April 2019).

Ledyaev V., Chirickova A., Seltser D. Who governs? Power in the local Russian community. Journal of Political Power, 2014, 7(2), pp. 211-231.

Ledyaev V.G., Chirikova A.E. Governors and local elites in Russia: patterns of interaction. European politics and society, 2019, 20(3), pp. 315-332.

Ledyaev V.G., Chirikova A. Power in local Russian communities: patterns of interaction between legislative and executive branches of local government. Urban Affairs Review, 2017, 53 (6), pp. 990-1024.

Ledyaev V., Chirikova A. Business in the power structure of small Russian towns. Europe-Asia Studies, 2020, 72 (4), pp. 686-711.

Sorci P. (2015) Measuring the impact of a state's legal and organizational framework on social capital through system dynamics modeling. Rangsit Journal Of Social Sciences And Humanities, 2(2), pp. 49-65.

Turovsky R., Gaivoronsky Y. Russia's regions as winners and losers: Political motives and outcomes in the distribution of federal government transfers. European Politics and Society, 2017, 18(4), pp. P. 529-551. 